\title{
Stay late or start early? Experimental evidence on the benefits of college matriculation support from high schools versus colleges
}

\author{
Benjamin L. Castleman ${ }^{\mathrm{a}, *}$, Laura Owen ${ }^{\mathrm{b}, *}$, Lindsay C. Page ${ }^{\mathrm{c}, *}$ \\ a University of Virginia, Curry School of Education, 1 Bonnycastle, Station \#1, Charlottesville, VA 22904, United States \\ ${ }^{\mathrm{b}}$ College of Education, San Diego State University, 5500 Campanile Drive, San Diego, CA 92182-1179, United States \\ ' University of Pittsburgh School of Education, 5918 WWPH, 230 South Bouquet Street, Pittsburgh, PA 15260, United States
}

\section{A R T I C L E I N F O}

\section{Article history:}

Received 26 November 2014

Revised 7 May 2015

Accepted 14 May 2015

Available online 11 June 2015

\section{JEL classification:}

I21

$\mathrm{I} 24$

Keywords:

College access

Summer melt

High school-university partnership

Randomized controlled trial

\begin{abstract}
A B S T R A C T
The summer melt and academic mismatch literatures have focused largely on college-ready, low-income students. Yet, a broader population of students may also benefit from additional support in formulating and realizing their college plans. We investigate the impact of a unique high school-university partnership to support college-intending students to follow through on their college plans. Specifically, we facilitated a collaborative effort between the Albuquerque Public Schools (APS) and the University of New Mexico (UNM), and randomly assigned 1602 APS graduates admitted to UNM across three experimental conditions: (1) outreach from an APS-based counselor; (2) outreach from a UNM-based counselor; or (3) the control group. Among Hispanic males, who are underrepresented at UNM compared to their APS graduating class, summer outreach improved timely postsecondary matriculation, with suggestive evidence that college-based outreach may be particularly effective. This finding is consistent with the social-psychological literature showing that increasing students' sense of belonging at college can improve enrollment outcomes.
\end{abstract}

(c) 2015 Elsevier Ltd. All rights reserved.

\section{Introduction}

Though the economic and non-pecuniary benefits of postsecondary education continue to grow, disparities in college access and success by family income, race/ethnicity, and gender have only widened over time (Bailey \& Dynarski, 2011; Goldin, Katz, \& Kuziemko, 2006). Responding to these inequalities has emerged as a top policy priority, as evidenced by the White House Summits on Expanding College Opportunity in January and December 2014. Within this context, recent research has focused on the role of information and access to college advising in whether academically-ready students successfully matriculate at

* Corresponding authors. Tel.: +1 617299 0279, +1 619594 0829, +1 4126487166 .

E-mail addresses: castleman@virginia.edu (B.L. Castleman), lowen@mail.sdsu.edu (L. Owen), lpage@pitt.edu (L.C. Page). colleges and universities that are well-matched to their abilities (Bettinger, Long, Oreopolous, \& Sanbonmatsu, 2012; Castleman, 2015; Castleman \& Page, 2014a; Hoxby \& Avery, 2013; Scott-Clayton, 2015). For instance, a substantial share of academically-prepared, college-intending high school graduates succumb to "summer melt" and fail to enroll anywhere in the year following high school, or do not attend the quality of institution (measured, for instance, by median SAT scores or graduation rates) at which they have the academic credentials to be admitted (Castleman \& Page, 2014a, 2014b; Hoxby \& Avery, 2013; Smith, Pender, \& Howell, 2013). Relatedly, providing students with personalized information about college and financial aid and/or the offer of additional college advising can generate substantial improvements in college access and persistence, at a low cost per student served (Castleman \& Page, 2015; Castleman, Page, \& Schooley, 2014; Hoxby \& Turner, 2013).

To date, the summer melt and academic mismatch literatures have focused largely on college-ready students from 
low-income backgrounds. Yet, college-ready students from other populations underrepresented in higher education may also struggle both to formulate and to follow through on their college intentions and may therefore benefit from additional information and personalized support to define and realize these goals. As informed by the social psychology literature, students of color may be hindered in formulating and realizing well-aligned postsecondary plans due to a diminished sense of belonging at postsecondary institutions. Rather, these students may perceive colleges and universities to be primarily the domain of affluent, white students (Walton \& Cohen, 2007). They may also be concerned that they would need to downplay their group identity in order to succeed in college (Cohen \& Garcia, 2005). If this lack of belonging stands as a barrier, students may be well served by colleges and universities extending a more "welcoming hand" to recent high school graduates as they make the transition to postsecondary education.

We unite these research strands by investigating the impact of a unique high school-university partnership designed to support under-represented, college-intending students to follow through on their college intentions. In summer 2012, we facilitated a collaborative effort between the Albuquerque Public Schools (APS) and the University of New Mexico (UNM), the higher education institution attended by the vast majority of APS graduates who continue on to a fouryear college or university. We randomly assigned the 1602 APS graduates who reported plans to enroll in UNM the following fall to one of three experimental groups: (1) outreach from a high school counselor stationed at an APS high school, (2) outreach from a high school counselor stationed on the UNM campus, or (3) to a control group. This experimental design allowed us to assess whether students are more responsive to the offer of outreach and support with the transition from high school to college when it comes from the college or from the high school.

As preview, we observe substantial variation in the impact of the summer outreach on students' initial college enrollment outcomes. Among students from demographic groups which are well-represented on the UNM campus - white students and female students - outreach and the offer of summer assistance have no effect on timely enrollment. Regardless of outreach, over $90 \%$ of APS students from these groups matriculated to college successfully in the year following high school.

In contrast, the rate of summer melt for Latino males exceeds $15 \%$ in the control group. This sub-group makes up $26 \%$ of all APS high school graduates but only $18 \%$ of APS graduates admitted to UNM and only $13 \%$ of the UNM population. ${ }^{1}$ This disproportionate rate of summer melt is consistent with broader trends revealing that Latino males are substantially underrepresented in higher education relative to their Latina and white peers (Castellanos, Gloria, \& Kamimura, 2006; Hurtado, Saenz, Santos, \& Cabrera, 2008; Lee \& Rawls, 2010; Roderick, Nagaoka, Coca, \& Moeller, 2008; Saenz \& Ponjuan, 2008). Encouragingly, we observe that for Latino males summer outreach was effective at improving

\footnotetext{
${ }^{1}$ For more information on the demographic composition of the UNM student body, see: http://oia.unm.edu/documents/enrollment-reports/fall2013-official-enrollment-report.pdf.
}

timely postsecondary enrollment. Further, we observe suggestive evidence that outreach from the college side was particularly effective, generating a more than 10 percentage point increase in fall matriculation. This latter finding is consistent with social psychological theory that proactive efforts to increase students' sense of belonging at a college or university should generate positive impacts on their enrollment decisions (Stephens, Hamedani, \& Destin, 2014; Walton \& Cohen, 2011).

We organize the remainder of the paper as follows. In Section 2, we review the economics and psychology literature relevant to interventions aimed at improving postsecondary access and success. In Section 3, we describe our research design, including the site, data and sample; the design of the intervention; and the process of and timeline for randomization. In Section 4, we present our results. In Section 5, we conclude with a discussion of these findings and their implications for policy, practice, and further research.

\section{Literature review}

Academically prepared students stand to realize large economic returns to college (Baum, Ma, \& Payea, 2013; Goldin \& Katz, 2008). These returns are particularly pronounced if students attend selective institutions, and should substantially exceed the cost of college net of financial aid (Dale \& Krueger, 2014; Long, 2010). Traditional human capital models suggest that, given these large returns relative to the net costs of college, students should choose higher education over alternative postsecondary options, such as direct entry into the labor market, particularly as wages for high school diploma holders continue to decline (Becker, 1964; Goldin \& Katz, 2008). Yet, as many as half of students from lower socio-economic backgrounds do not apply to academicallyrigorous institutions to which, based on their credentials, they would have a good chance of being admitted (Hoxby \& Avery, 2013; Smith, Pender, \& Howell, 2013). This is especially true for African American and Hispanic students who also often lack access to social networks and adequate college counseling to support and provide valuable information to navigate the complex college admissions and financial aid process (Bryan, Moore-Thomas, Day-Vines, \& HolcombMcCoy, 2009). Further, even among students who have been accepted to college, in many cases applied for financial aid, and chosen where to enroll as of high school graduation, 10$20 \%$ fail to matriculate anywhere in the year following high school (Castleman \& Page, 2014a).

There are various reasons why even academicallyaccomplished students who have been admitted to college may nonetheless fail to successfully matriculate. Students may be unaware of important stages in or hindered by the complexity of the financial aid process. For instance, a substantial share of students who have applied for financial aid are required by the United States Department of Education to verify the income or asset information they provided on the Free Application for Federal Student Aid (FAFSA). Further, students from lower-income families who might be most challenged by the verification process are flagged for verification at higher than average rates (Castleman \& Page, 2014a). In addition, the channels through which students are notified about FAFSA verification may not effectively reach them 
(Castleman, 2015; Castleman \& Page, 2014a). Students may be surprised by costs they did not anticipate, such as fees associated with attending orientation or completing housing forms, and either face liquidity constraints or be unwilling to absorb near-term costs even given the probability of large pay-offs in the future (Goodman, 2013; Klasik, 2012; Pallais, 2013). Faced with the complexity of completing various financial and procedural tasks required for matriculation and occupied with various family, friendship, and work commitments, students may procrastinate on completing required tasks and miss important deadlines (Castleman, 2015; Castleman \& Page, 2014a; Karlan, McConnell, Mullainathan, \& Zinman, 2010).

An alternative set of explanations for why some collegeready students may not matriculate emerges from social psychological research. Traditionally marginalized groups, including students of color, may observe the absence of others who are similar to them (Constantine, Kindaichi, \& Miville, 2007) and question whether they belong on campus and whether students "like them" can succeed in a collegiate environment. This uncertainty may lead to anxiety about whether their academic performance will confirm negative societal stereotypes about their social group (Stephens et al., 2014; Walton \& Cohen, 2011; Yeager \& Dweck, 2012; Yeager \& Walton, 2011). Increased stress and anxiety may further impede students' ability to complete required tasks over the summer (Lovelace \& Rosen, 1996). For first-generation college-goers, uncertainty about what life in college would be like may lead students to be heavily influenced by the postsecondary decisions of peers in their schools and social networks (Cialdini, 2001; White, Hogg, \& Terry, 2002).

Encouragingly, evidence from several field experiments demonstrates that providing students with additional information and the offer of assistance can help them to overcome these informational, procedural and behavioral challenges and can, in turn, improve their college outcomes. For instance, students whose parents received assistance completing the FAFSA as part of the income tax preparation process were substantially more likely to enroll and persist in college (Bettinger et al., 2012). High-achieving, low-income students who received semi-customized guidance about college and financial aid along with application fee waivers were substantially more likely to enroll at colleges well-matched to their academic abilities (Hoxby \& Turner, 2013). High school seniors and recent graduates who received individualized assistance and encouragement from peer mentors enrolled in college at higher rates that students who did not receive peer outreach (Bos, Berman, Kane, \& Tseng, 2012; Carrell \& Sacerdote, 2013; Castleman \& Page, 2014b). Finally, high school graduates who received additional information and the offer of support during the summer after high school graduation, either through outreach from school- or community-based counselors or via personalized text message reminders of important tasks to complete, were more likely to enroll and persist in college than students who did not receive additional summer outreach (Castleman \& Page, 2014b; Castleman, Page, \& Schooley, 2014).

Interventions that promote a stronger sense of social belonging among underrepresented groups have also generated improved academic outcomes among students who have already matriculated in college. In one set of interventions, col- lege freshmen read narratives from seniors that described the challenge of adjusting to campus and developing a sense of belonging as a normal aspect of the transition to college. The freshmen were then asked to record a video for future students describing how their own college experiences to date reflected these narratives (Walton \& Cohen, 2011). In another intervention, a panel of juniors and seniors shared stories with incoming freshmen of how their social class had affected their college experience, creating both challenges and opportunities on campus (Stephens et al., 2014). The panel also described how they had developed success strategies that took their social background into consideration. Both interventions, while low-touch, reduced academic achievement gaps. For example, Stephens et al. (2014) find that their freshman-focused intervention led to a $63 \%$ reduction in the gap in GPA between first-generation students and their peers with college-educated parents. These efforts point to the potential promise of further intervention to improve students' sense of social belonging even before they are on their college campus (Yeager \& Walton, 2011).

\subsection{Outreach from the secondary versus post-secondary sector to improve students' college outcomes}

From a policy perspective, it is unclear whether secondary schools or higher education institutions should take the lead in supporting students in the summer after high school graduation. During this period, students are no longer officially members of their high school community, but they have yet to formally matriculate or actively engage with supports available at their intended college. On the one hand, high school counselors typically work on ten-month contracts and so are, in theory, available to support summer outreach efforts. These counselors also bring important familiarity with the high school context from which students graduated. On the other hand, university staff members bring institutionspecific expertise and potentially detailed information on which transition tasks students have and have not completed. $^{2}$ Students may also be more responsive to outreach from the university where they have indicated an intention to enroll rather than from the school system from which they just graduated. It is therefore an open question whether high school- or university-side summer outreach would have a greater impact on students' postsecondary outcomes.

Our research questions focus on investigating whether college-ready, college-intending recent high school graduates benefit equally or differentially from summer transition outreach when it is delivered from the high school versus postsecondary sector. Specifically, we investigate the following questions:

1. Do students who receive proactive outreach from a high school- or college-based counselor during the summer enroll in college at higher rates than students who do not receive outreach?

\footnotetext{
2 In the case of the intervention on which we report, UNM administrators were not able to provide APS counselors stationed at UNM with real-time information about which tasks students completed over the summer.
} 
Table 1

Descriptive statistics for Class of 2012 APS high school graduates intending to enroll in the University of New Mexico.

\begin{tabular}{lcc}
\hline & UNM-intending students $(N=1602)$ & All other APS graduates $(N=2615)$ \\
\hline Male & 0.408 & 0.517 \\
Hispanic & 0.501 & 0.629 \\
Black & 0.021 & 0.031 \\
White & 0.848 & 0.846 \\
Asian & 0.046 & 0.018 \\
Free/reduced price lunch eligible & 0.288 & 0.496 \\
English language learner & 0.014 & 0.076 \\
State standardized test in mathematics, grade 11 & 1144.348 & 1135.887 \\
& $(7.486)$ & $(10.023)$ \\
State standardized test in English Language arts, grade 11 & 1146.619 & {$[2355]$} \\
& $(7.090)$ & 1138.688 \\
High school GPA & {$[1548]$} & $(9.107)$ \\
& $(0.422)$ & {$[2351]$} \\
& {$[2.262$} & $(0.599)$ \\
\hline
\end{tabular}

Source: Albuquerque Public Schools administrative records.

Notes: Standard deviations are shown in parentheses (for continuous variables only) and the number of observations is shown in brackets if less than the full analytic sample.

2. Are students differentially responsive to outreach from counselors stationed at a university versus counselors stationed at their high school?

3. Are these sources of outreach differentially effective at improving timely postsecondary enrollment among college-intending recent high school graduates?

\section{Research design}

\subsection{Sites}

During the summer of 2012, we implemented the intervention in collaboration with two educational agencies: the Albuquerque Public Schools (APS) in Albuquerque, NM, and the University of New Mexico, the state's flagship institution, also in Albuquerque. APS is a large, urban school district, graduating approximately 4500 seniors each year. APS is somewhat unique in that the majority of college-going high school graduates attend one of just two postsecondary institutions. This is in contrast to other urban settings where we typically observe that the majority of recent graduates who continue to postsecondary education attend one of among 10-15 institutions (Castleman \& Page, 2014b, 2015). Specifically, across the APS graduating classes of 2007 through 2011, of those who continued on to postsecondary education, $45 \%$ attended the University of New Mexico (UNM) and $36 \%$ attended the Central New Mexico Community College (CNM), also located in Albuquerque. Beyond these two, the next most common postsecondary institution was New Mexico State, which received nearly $5 \%$ of college-going APS graduates (Strategic Data Project, 2014).

\subsection{Data and sample}

Our investigation capitalizes on several data sources. First, APS provided student-level demographic and prior achievement information, including gender, race/ethnicity, free/reduced price lunch status, FAFSA completion status, high school GPA, and scaled scores on state achievement tests in math and English language arts (ELA). Second, APS main- tained and provided interaction-level records from counselor interaction logs, which include information on whether students took up the offer of help; when and where interactions took place, and what help students received. Third, APS obtained student-level college enrollment outcomes from the National Student Clearinghouse, a non-profit organization that maintains postsecondary enrollment records at approximately $96 \%$ of colleges and universities in the U.S. ${ }^{3}$

The experimental sample includes Class of 2012 high school graduates who had been admitted to UNM. ${ }^{4}$ These 1602 students accounted for $38 \%$ of the 2012 APS graduates $(N=4217)$. In Table 1 , we provide descriptive statistics comparing the experimental sample of students who had been admitted to UNM (column 1) to all other high school graduates in the district (column 2). UNM-admitted students were substantially less likely to be male ( $41 \%$ versus $52 \%$ among all APS graduates). This gender imbalance is consistent with the UNM population as a whole. For example, in the Fall of 2013, $56 \%$ of the UNM undergraduate student body was female. In addition, the UNM-admitted APS graduates were substantially less likely to qualify for free- or reduced-price lunch ( $29 \%$ versus $50 \%$ ), and had substantially higher GPAs (3.26 versus 2.51). UNM-admitted students were also less likely to be Hispanic and had higher scores on state math and ELA exams. In short, the experimental sample of students appeared more poised for collegiate success-and more representative of a traditional flagship university population-than the full cohort of APS graduates.

Further, this sample of students is higher performing, on average, than students targeted by prior summer melt interventions (Castleman \& Page, 2015; Castleman, Page, \& Schooley, 2014). Therefore, we may reasonably expect lower rates of summer melt among these UNM-admitted students,

\footnotetext{
${ }^{3}$ NSC coverage rates vary considerably by state. Fortunately, the coverage rates are fairly high in New Mexico (90.2\%), where the majority of students in our experimental sample attend college (Dynarski, Hemelt, \& Hyman, 2015).

${ }^{4}$ Prior to the start of the intervention UNM transferred to APS a list of all high school seniors from the district who had been admitted to the university.
} 
given prior descriptive evidence that summer melt is more prevalent among students with lower levels of prior academic achievement (Castleman \& Page, 2014a). Nevertheless, related descriptive evidence suggests a "vanishing" of Latino males from the higher education pipeline (Saenz \& Ponjuan, 2008). The challenges that Latino/a students overall and Latino males specifically experience in access and success in higher education motivate our attention to rates of summer melt and to this intervention's impacts for subgroups defined by gender and Hispanic origin (Castellanos et al., 2006; Hurtado et al., 2008; Roderick et al., 2008; Saenz \& Ponjuan, 2008). Of the Hispanic students in our sample, $42 \%$ qualified for free or reduced-price school meals, and they had an average high school GPA of 3.18.

\subsection{Intervention design}

APS retained 21 regular school-year counselors to staff the APS-UNM intervention over the summer. Based on our interactions with counselors and the in-person training we conducted, participating counselors varied considerably in the extent to which they had worked with students on financial aid issues and college transition tasks. Therefore, the impacts we observe might understate those that full-time college advisors might have on students' ability to successfully transition to college. At the same time, these counselors had self-selected to work with students on their college transition during the summer months, and had considerable experience working with students on college/career readiness as well as a broad range of social-emotional issues. Therefore the effects we observe might overstate the impact of having other members of a college community (e.g. students or faculty) provide summer support.

Eight counselors were based at UNM, and 13 were based at APS high schools. Counselors worked 10-20 hours per week for a period of 5-6 weeks. Counselor caseloads ranged from 60 to 100 students, with larger caseloads assigned to counselors who were able to invest more hours in the project. We did not randomly assign counselors to work either from UNM or APS; rather, the head of counseling for the district assigned participating counselors to one of the two work locations. We do not have access to counselor-level characteristics such as years of experience to assess whether the counselors assigned to work from UNM versus APS appear to be systematically different on observable characteristics. Nevertheless, our best understanding was that she worked to evenly distribute counselor quality across the two locations.

APS counselors stationed either at APS high schools or at UNM proactively reached out to students via several channels, including phone, email and text messaging. Counselors offered students help completing required summer tasks, which ranged from finalizing financial aid, evaluating supplementary loan options and comparing tuition payment plans to completing procedural tasks like registering for orientation and academic placement tests. Counselors provided support through both in-person and phone meetings. Prior to the start of summer, we provided a comprehensive training for school counselors on how to review financial aid award letters and tuition bills and access and complete required college paperwork. Our team developed a number of tools to help guide counselors' interactions with students, including comprehensive checklists of what to cover when they met with students. Counselors documented their conversations and meetings with students from both the treatment and control groups in an online interaction log.

Counselors stationed at the university campus received several additional supports. First, in addition to the training we provided, the university provided a day-long, oncampus orientation to the college-based counselors. The orientation covered university-specific details on required summer tasks, as well as an introduction to campus staff and resources that were available to assist students. Second, the university identified a staff liaison who was available throughout the summer to answer questions for the collegebased counselors. Third, the university provided office space and landlines from which the counselors could contact students.

It is important to note that this intervention design capitalizes on the uniquely strong "feeder pattern" between APS and UNM. While the particular structure of the intervention, with high school counselors staffing outreach from UNM to UNM-admitted students, may not translate well to other locations in the US, our results nevertheless provide insight regarding effective strategies for reducing summer melt and the role that postsecondary institutions may productively play in improving students' start to postsecondary education.

\subsection{Randomization}

An APS data analyst conducted the random assignment of students to experimental conditions prior to the start of summer. Randomization was done within students' graduating high school, with the experimental sample divided roughly equally among the control $(N=528)$ and two treatment groups ( $N=539$ for counselors stationed at UNM and $N=535$ for counselors stationed at APS).

In Tables 2 and 3, we assess the baseline equivalence of the treatment and control groups. In Table 2, we present group means after accounting for school membership with fixed effects. There are no significant differences between the control group and the experimental group assigned to outreach from counselors at UNM on any of the baseline characteristics we considered. Students randomly assigned to receive outreach from counselors at APS had slightly higher shares of Asian students than the control group (5.8\% versus $3.1 \%$ ) and slightly higher GPAs (3.28 versus 3.23). However, with thirty individual tests for baseline equivalence we would expect 1-2 significant differences simply as a result of Type I error. As an added check, we ran tests to assess balance on covariates jointly (Hansen \& Bowers, 2008). We tested differences between the two treatment groups as well as between each treatment and the control group. None of the tests indicated significant group differences among the baseline characteristics (with the $p$-value being above .10 in all cases). In Table 3, we present p-values associated with these omnibus tests for the sample overall as well for subgroups defined by gender and Hispanic origin. Taken together, we conclude that randomization was successful in establishing experimental groups that were statistically equivalent at baseline, both for the sample overall and for the subgroups examined. 
Table 2

Assessing balance in covariates across experimental groups.

\begin{tabular}{lccc}
\hline & Control $(N=528)$ & UNM outreach $(N=539)$ & APS outreach $(N=535)$ \\
\hline Male & 0.428 & 0.386 & 0.410 \\
Hispanic & 0.503 & 0.487 & 0.514 \\
Black & 0.824 & 0.855 & 0.866 \\
White & 0.025 & 0.017 & 0.022 \\
Asian & 0.031 & 0.050 & $0.058^{*}$ \\
Free/reduced price lunch eligible & 0.287 & 0.284 & 0.293 \\
English language learner & 0.009 & 0.013 & 0.019 \\
State standardized test in mathematics, grade 11 & 1144.268 & 1144.260 & 1144.516 \\
State standardized test in English Language arts, grade 11 & 1146.644 & 1146.535 & 1146.679 \\
High school GPA & 3.232 & 3.269 & $3.284^{*}$ \\
\hline
\end{tabular}

Source: Albuquerque Public Schools administrative records.

Notes: Cells report group means after accounting for school membership. Notation of statistical significance refers to comparisons between control and treatment group means after accounting for school membership with fixed effects. ${ }^{*} p<0.05,{ }^{* *} p<0.01 .{ }^{* * *} p<0.001$.

Table 3

$p$-values from omnibus tests of baseline covariate equivalence overall and in subgroups defined by ethnicity and gender.

\begin{tabular}{llll}
\hline & APS versus control & UNM versus control & UNM versus APS \\
\hline Overall & 0.118 & 0.696 & 0.525 \\
Hispanic, male & 0.102 & 0.813 & 0.184 \\
Non-Hispanic, male & 0.822 & 0.538 & 0.548 \\
Hispanic, female & 0.998 & 0.226 & 0.195 \\
Non-Hispanic, female & 0.113 & 0.722 & 0.602 \\
\hline
\end{tabular}

Source: Albuquerque Public Schools administrative records.

Notes: Cells report p-values based on Hansen and Bowers' (2008) omnibus test for assessing baseline equivalence.

\subsection{Measures}

To evaluate the impact of the interventions on college enrollment in the fall semester following high school graduation, we focus primarily on binary indicators for whether students enrolled in any college; at UNM specifically; or at a college other than UNM in the fall semester following graduation. Given that our enrollment data comes from the NSC, we have access to students' college-going outcomes regardless of their actual level of participation in the intervention, and therefore the validity of our findings is not threatened by any sample attrition. The explanatory variables of primary interest are indicators for the experimental group to which each student was assigned. We incorporate the academic and demographic covariates described in Table 1 in our analyses to increase precision of our estimates. We include indicators for missingness for covariates with missing values and fixed effects for students' high school since randomization was conducted at the student level within each high school.

\subsection{Empirical strategy}

To investigate the impact of the APS-UNM intervention, we utilize linear probability models. ${ }^{5}$ We specify the Intent-

\footnotetext{
5 We also assessed the sensitivity of our results to model choice by refitting all outcome models utilizing a probit specification. We find that results are consistent across specifications (results available upon request).
}

to-Treat (ITT) models of the following general form:

$$
\operatorname{COLLEGE}_{i j}=\alpha_{j}+\beta_{1} U N M_{i j}+\beta_{2} A P S_{i j}+\mathbf{X}_{\mathbf{i j}} \gamma+\varepsilon_{i j},
$$

where $\alpha_{j}$ represents a vector of fixed effects for high school; $U N M_{i j}$ is an indicator for student $i$ in school $j$ receiving outreach from an APS counselor stationed at UNM; $A P S_{i j}$ is an indicator for receiving outreach from an APS counselor stationed at the APS high school from which the student just graduated; $\mathbf{X}_{\mathbf{i j}}$ is a vector of student-level covariates; and $\varepsilon_{i j}$ is a residual error term. Our estimates of the $\beta_{1}$ and $\beta_{2}$ coefficients will indicate whether assigning students to outreach from an APS counselor stationed at UNM or to outreach from an APS counselor stationed at an APS high school respectively increased college attainment relative to students who did not receive proactive outreach. A post-hoc $F$-test on the $\beta_{1}$ and $\beta_{2}$ coefficients will indicate whether assigning students to outreach from a counselor at UNM had a different impact on attainment compared to assigning students to outreach from a counselor stationed at their APS high school.

Among Hispanic students at UNM, 42\% are male and 58\% are female. Among Hispanic UNM-admits from APS, the gender imbalance is even more extreme, with $64 \%$ being female and $36 \%$ being male. Among non-Hispanic students the gender imbalance is less extreme and is similar at UNM and among UNM-admits from APS. Given the substantial underrepresentation of Hispanic male students among those admitted to and attending UNM, we are particularly interested in whether there are heterogeneous effects of summer outreach among this sub-group. We therefore examine whether the treatments had larger effects for Hispanic males, relative 
Table 4

Intervention take up, for subgroups defined by ethnicity and gender.

\begin{tabular}{|c|c|c|c|c|c|}
\hline & Overall & Hispanic, male & Non-Hispanic, male & Hispanic, female & Non-Hispanic, female \\
\hline $\begin{array}{l}\text { Overall take-up } \\
\text { Any outreach }\end{array}$ & $\begin{array}{l}0.521^{* * *} \\
(0.038)\end{array}$ & $\begin{array}{l}0.502^{* * *} \\
(0.015)\end{array}$ & $\begin{array}{l}0.458^{* * *} \\
(0.035)\end{array}$ & $\begin{array}{l}0.499^{* * *} \\
(0.028)\end{array}$ & $\begin{array}{l}0.529^{* * * *} \\
(0.031)\end{array}$ \\
\hline $\begin{array}{l}\text { Fixed effects for high school } \\
N \\
R^{2}\end{array}$ & $\begin{array}{l}\sqrt{ } \\
1602 \\
0.341\end{array}$ & $\begin{array}{l}\sqrt{ } \\
290 \\
0.29\end{array}$ & $\begin{array}{l}\sqrt{ } \\
364 \\
0.284\end{array}$ & $\begin{array}{l}\sqrt{ } \\
513 \\
0.306\end{array}$ & $\begin{array}{l}\sqrt{ } \\
435 \\
0.334\end{array}$ \\
\hline $\begin{array}{l}\text { Take-up by source of outreach } \\
\text { UNM outreach }\end{array}$ & $\begin{array}{l}0.550^{* * * *} \\
(0.021)\end{array}$ & $\begin{array}{l}0.600^{* * *} \\
(0.052)\end{array}$ & $\begin{array}{l}0.523^{\text {**** }} \\
(0.048)\end{array}$ & $\begin{array}{l}0.552^{* * * *} \\
(0.036)\end{array}$ & $\begin{array}{l}0.549 \text { *** } \\
(0.039)\end{array}$ \\
\hline APS outreach & $\begin{array}{l}0.453^{* * * *} \\
(0.022)\end{array}$ & $\begin{array}{l}0.455^{* * *} \\
(0.051)\end{array}$ & $\begin{array}{l}0.396^{* * *} \\
(0.048)\end{array}$ & $\begin{array}{l}0.443 * * * \\
(0.039)\end{array}$ & $\begin{array}{l}0.509^{* * * *} \\
(0.044)\end{array}$ \\
\hline Control group take-up rate & 0.009 & -0.002 & -0.005 & -0.001 & -0.009 \\
\hline
\end{tabular}

Source: Albuquerque Public Schools administrative records.

Notes: Coefficients presented from linear probability models predicting treatment take-up from randomized treatment assignment and fixed effects for high school. Notation of statistical significance refers to comparisons between control and treatment group means after accounting for school membership with fixed effects. Essentially no control group student received support from either a UNMor APS-based counselor. The F-test pertains to a post-hoc comparison of the rate of take-up of the UNM-based and APS-based outreach. ${ }^{*} p<0.05 .{ }^{* *} p<0.01$.

*** $p<0.001$.

to the effects for Hispanic females and for non-Hispanic students.

\section{Results}

\subsection{Intervention implementation}

In Table 4 we present results on the share of students that met with an APS counselor during the summer. In the top panel we focus on overall take-up, and in the bottom panel we investigate take-up rates by whether outreach came from APS counselors stationed at an APS high school or at UNM. Overall, just over $52 \%$ of students in the treatment group met with a counselor during the summer months, while virtually no students in the control group met with a counselor (column 1). Take-up was also fairly consistent across ethnicity and gender: $50.2 \%$ of Hispanic males met with a counselor, on par with the share of Hispanic females (49.9\%) and non-Hispanic females (52.9\%) that did so. The share of nonHispanic males that met with a counselor was somewhat lower (45.8\%). Students were significantly more responsive to the offer of assistance when it came from counselors stationed at UNM. Overall, 55\% of students who received outreach from UNM met with a counselor, compared with $45.3 \%$ of students who received outreach from a counselor at an APS high school. Hispanic males were particularly responsive to outreach from counselors at UNM relative to counselors at APS high schools (60\% versus $45.3 \%$ ). Similar margins held for non-Hispanic males and Hispanic females, while the take-up rates were more consistent across source of outreach for nonHispanic females.

In Table 5 we present the results of the summer outreach on whether students enroll in college, both overall and disaggregated by ethnicity and gender. We present these results overall (top panel) and by whether students received outreach from counselors at UNM or APS (bottom panel). Overall, we find no effect of the intervention on whether students enrolled in college (column 1), but this null finding masks considerable heterogeneity across sub-groups. While only $84 \%$ of Hispanic males in the control group enrolled in college, proactive summer outreach increased on-time enrollment among these students by almost ten percentage points. We find suggestive evidence that Hispanic males were particularly impacted by outreach from counselors at UNM relative to counselors at APS (11.7 percentage point increase versus a 7.6 percentage point increase), though these two impact estimates are not statistically distinguishable. By comparison, we do not find evidence of positive effects for any of the other sub-groups of students.

The impacts that we observe for Hispanic males are large in magnitude, although it is important that we underscore them as exploratory in nature. While we did not specify an examination of sub-group effects defined by ethnicity and gender in advance, the sizeable effects for this subgroup are consistent with the existing literature on the underrepresentation of Latinos and of Latino males, in particular, in postsecondary education. Further, when we adjust our threshold for statistical significance to account for multiple comparisons using a straightforward (but conservative) Bonferroni procedure, the effect associated with UNM-based outreach remains significant (Schochet, 2008). Taken together, we regard these findings as an indication that, even among relatively high-performing students admitted to a state flagship institution, certain subgroups may benefit, in particular, from summer outreach and support in order to successfully matriculate to college on time.

Table 5 also reveals scattered, although not significant, negative impacts of outreach for students besides Hispanic males. To assess whether there was evidence of a negative 
Table 5

Impact of the offer of summer support on college enrollment, subgroups defined by ethnicity and gender.

\begin{tabular}{|c|c|c|c|c|c|}
\hline & Overall & Hispanic, male & Non-Hispanic, male & Hispanic, female & Non-Hispanic, female \\
\hline \multicolumn{6}{|l|}{ Overall take-up } \\
\hline Any outreach & $\begin{array}{c}-0.001 \\
(0.015)\end{array}$ & $\begin{array}{l}0.095^{*} \\
(0.044)\end{array}$ & $\begin{array}{l}-0.014 \\
(0.034)\end{array}$ & $\begin{array}{l}-0.011 \\
(0.025)\end{array}$ & $\begin{array}{l}-0.026 \\
(0.023)\end{array}$ \\
\hline Fixed effects for high school & $\sqrt{ }$ & $\sqrt{ }$ & $\sqrt{ }$ & $\sqrt{ }$ & $\sqrt{ }$ \\
\hline Covariate controls & $\sqrt{ }$ & $\sqrt{ }$ & $\sqrt{ }$ & $\sqrt{ }$ & $\sqrt{ }$ \\
\hline$N$ & 1602 & 290 & 364 & 513 & 435 \\
\hline$R^{2}$ & 0.018 & 0.097 & 0.08 & 0.063 & 0.044 \\
\hline \multicolumn{6}{|l|}{ Take-up by source of outreach } \\
\hline UNM outreach & $\begin{array}{l}0.006 \\
(0.016)\end{array}$ & $\begin{array}{l}0.117^{* * *} \\
(0.045)\end{array}$ & $\begin{array}{l}0.016 \\
(0.039)\end{array}$ & $\begin{array}{c}-0.018 \\
(0.029)\end{array}$ & $\begin{array}{c}-0.029 \\
(0.027)\end{array}$ \\
\hline APS outreach & $\begin{array}{l}-0.009 \\
(0.017)\end{array}$ & $\begin{array}{l}0.076 \\
(0.051)\end{array}$ & $\begin{array}{l}-0.042 \\
(0.040)\end{array}$ & $\begin{array}{c}-0.004 \\
(0.029)\end{array}$ & $\begin{array}{c}-0.024 \\
(0.028)\end{array}$ \\
\hline Control group enrollment rate & 0.918 & 0.840 & 0.910 & 0.930 & 0.960 \\
\hline Fixed effects for high school & $\sqrt{ }$ & $\sqrt{ }$ & $\sqrt{ }$ & $\sqrt{ }$ & $\sqrt{ }$ \\
\hline Covariate controls & $\sqrt{ }$ & $\sqrt{ }$ & $\sqrt{ }$ & $\sqrt{ }$ & $\sqrt{ }$ \\
\hline$N$ & 1602 & 290 & 364 & 513 & 435 \\
\hline$R^{2}$ & 0.019 & 0.099 & 0.086 & 0.064 & 0.044 \\
\hline F-test & 0.87 & 1.19 & 1.93 & 0.26 & 0.03 \\
\hline ( $p$-value) & 0.3509 & 0.2766 & 0.1657 & 0.6090 & 0.8648 \\
\hline
\end{tabular}

Source: Albuquerque Public Schools administrative records and National Student Clearinghouse.

Notes: Coefficients presented from linear probability models predicting enrollment outcomes from randomized treatment assignment, fixed effects for high school, and baseline covariates. Baseline covariates include gender, race/ethnicity, FRL status, ELL status, high school GPA, performance on state standardized tests in math and ELA and indicators for missing baseline information. ${ }^{*} p<0.05$. ${ }^{* *} p<0.01 .{ }^{* * *} p<0.001$.

impact of summer outreach for students who were not Hispanic males, we pooled these students into a single group within which to assess the impact of the summer outreach. We found no evidence of a significant negative impact on summer outreach for these students, at any standard threshold of statistical significance.

A final question is whether counselor outreach is leading students to enroll at UNM specifically, or instead increasing overall college entry. Our sample is conditioned on being admitted to UNM. It is quite possible that some of these students were admitted to other institutions as well, and in some cases may have had superior options in terms of match, quality, and/or affordability. That being said, given the limitations of the higher education system in New Mexico, these other options are likely to have been out of state. While we trained counselors to support students to enroll wherever they intended to go to college, counselors stationed at UNM may have felt some implicit pressure to encourage enrollment at that institution specifically. For some students, this could potentially lead to sub-optimal enrollment outcomes. In Table 6 we present impacts of the intervention separately on enrollment at UNM and on enrollment at other colleges and universities, both overall and broken out by ethnicity and gender. For Hispanic males, outreach had similar impacts on enrollment at UNM and other campuses. For other subgroups, the patterns of parameter estimates suggest some shift from non-UNM campuses in favor of UNM. While we attempted to disaggregate these impacts by the source of outreach, the pattern of resulting coefficients, all imprecisely estimated, did not allow for strong conclusions. Finally, while not shown, the intervention had no unique impact on enrollment in a college or university in New Mexico, specifically.

\subsection{Cost effectiveness}

A final question we consider is whether the summer outreach efforts that we facilitated were a cost-effective approach to improving college access. The cost of this intervention was approximately $\$ 100$ per student served, primarily to cover the cost of counselors' time to provide outreach and follow-up support. This is similar to the cost associated with our prior counselor-led summer melt efforts (Castleman, Page, \& Schooley, 2014), and more expensive than our textbased efforts (Castleman \& Page, 2015), which substantially reduce the person-hours needed to conduct direct outreach. This per student cost admittedly does not include time devoted to the project by APS staff who managed the district's involvement in the intervention as well as UNM staff time devoted to training and supporting participating counselors. As presented above, the intervention had no overall impacts on timely college enrollment. Overall enrollment rates were high for this sample of student, regardless of whether they received outreach. Given this, one might judge that this is not a worthwhile investment. We argue that this is not the case for two key reasons.

First, the available data only allows examination of ontime, first-semester enrollment in college. While overall enrollment rates were high, previous descriptive evidence indicates that of all APS students who matriculate to college, only $80 \%$ persist to their sophomore year (Strategic Data Project, 2014). Therefore, the initial null impacts of the intervention for certain students may mask impacts that occur beyond the first semester if summer outreach and receipt of transitional support helps students get a better start to college. In prior summer melt interventions that we have conducted, we have found that treatment impacts persist and even grow 


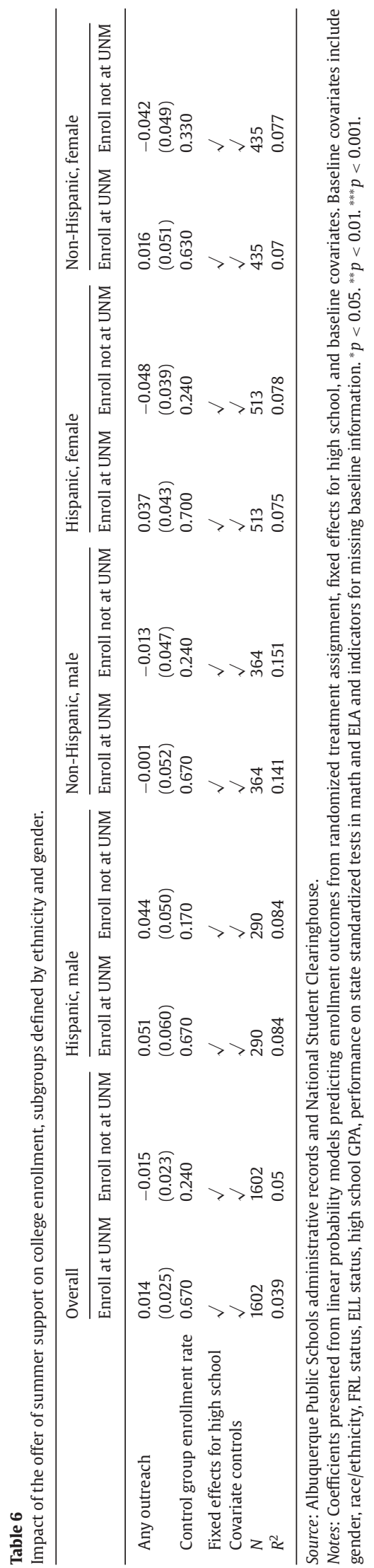

larger over time (Castleman, Page, \& Schooley, 2014). Therefore, we may expect to observe a delayed impact of summer outreach on college persistence, even among students who initially enrolled at high rates. Considering impacts only on first-semester enrollment may thus yield conservative estimates regarding overall program impacts (and as a result cost effectiveness).

Second, while the intervention provided outreach to many students who appeared not to need support to successfully transition to college, we did learn about the positive impacts for a salient subgroup of students, Hispanic males. Providing outreach to all UNM-admitted Hispanic males in the summer months would cost the district approximately $\$ 30,000$, given the 290 Hispanic male students in our sample overall. Our results suggest that this support would induce 27 additional students to enroll in college (271 treated students versus 244 control students). This translates to a cost of just over $\$ 1000$ per student supported to enroll in college. As a broad point of reference, existing research suggests that providing students with an additional $\$ 1000$ in grant-based financial aid improves college enrollment by 3-6 percentage points (Dynarski, 2003; Kane, 2003). Assuming additional financial aid generated a 6 percentage point improvement over the control group enrollment (moving enrollment from 244 students to nearly 259), the cost of providing such grant-based support would be over $\$ 250,000$, or $\$ 20,000$ per student induced to enroll as a result of the additional funding support. ${ }^{6}$ This point of comparison provides a benchmark for summer support as a cost-effective strategy for improving enrollment outcomes among potentially vulnerable populations.

As an additional point of comparison, we can also consider economic returns to additional years of schooling. In 2012, median income of young Hispanic adults (aged 25-34) with a high school diploma was approximately $\$ 28,000 .^{7} \mathrm{Ev}-$ idence indicates that returns to additional years of schooling are sizeable and that wage premiums to education for racial/ethnic minorities are particularly so (Card, 1999; Dale \& Krueger, 2014; Long, 2010). For example, utilizing data from the National Education Longitudinal Study of 1988, Long (2010) estimates an approximately $11 \%$ return in earnings for each additional year of education. If we conservatively assume that the summer outreach for all Hispanic males increased years of education by just one year for the 27 students induced to enroll, this would translate to an additional $\$ 83,000$ in annual earnings realized by these individuals collectively. Compared to the $\$ 30,000$ in implementation costs for a single cohort of students, these figures again suggest that the summer outreach is well worth the investment.

\section{Discussion}

Prior to this study, all of the summer melt interventions we have conducted involved outreach and support from

\footnotetext{
${ }^{6}$ We recognize that impact estimates utilized here may not be exactly comparable, given that potential interventions would be provided to students at different points in the college-going pipeline. In addition, the 3-6 percentage point impact does not pertain specifically to Hispanic males. We believe that this figure is nevertheless informative as one baseline for comparison.

7 http://nces.ed.gov/programs/digest/d13/tables/dt13_502.30.asp.
} 
high schools or from community-based organizations that focused primarily on secondary school students. Further, we are unaware of other interventions that rigorously investigate the efficacy of outreach from the higher education sector at reducing summer melt among college-intending high school graduates. There are various reasons, however, why outreach from colleges and universities might be particularly effective at increasing on-time enrollment rates, given that students have indicated interest or intention to enroll, and the institutions have much more detailed information about the college transition tasks that students have completed and those with which they are falling behind. Moreover, there are important policy questions about how responsibility for ensuring that college-intending high school graduates succeed in the transition to college ought to be distributed between the secondary and postsecondary sectors.

We sought to inform these questions by partnering with the Albuquerque Public Schools to implement a summer melt intervention focused specifically on a set of recent district graduates all of whom had gained acceptance to the state flagship institution, the University of New Mexico. Through the intervention, students were randomly assigned to receive summer outreach from a counselor stationed at a district high school, from a counselor stationed at the University of New Mexico, or to not receive summer outreach at all.

Different from prior summer melt interventions that we have implemented, focal students in this study were substantially higher performing than other students in their high schools and even other college-intending students in the district. In addition, they were far less likely to be from lowincome households; $29 \%$ of the UNM admits from APS qualified for subsidized school meals, compared to approximately half of all district graduates. Given the relative high academic achievement and lower incidence of low-income status of these students, it is perhaps unsurprising that the on-time enrollment rate for students in our sample was over $90 \%$ across experimental groups.

This is not to say, however, that these students' transition to college was entirely seamless. More than half of students who received proactive outreach took up the opportunity to interact with a counselor over the summer. Counselor interaction logs indicate that students sought support with a variety of college transition tasks, including completing the FAFSA, finalizing financial aid and managing finances; arranging on-campus housing; understanding placement tests and selecting classes; and organizing transportation to campus. Counselors also assisted students with logistical and paperwork-related concerns such as obtaining a final high school transcript and logging into the university web portal to access email, check housing status, and determine accurate submission of documents. And while large shares of students responded to outreach regardless of its source, students were substantially more responsive to outreach when it was presented as coming from the university rather than from the high school system from which they just graduated (overall response rates were $55 \%$ and $45 \%$, respectively).

An admitted limitation of our study design is that, while students were assigned at random to outreach either from the secondary or postsecondary side, we were not able to assign counselors at random to their outreach post. The APS head of counseling handled counselor assignment, and while our best understanding is that she worked to evenly distribute counselors according to experience and perceived quality, we lack access to counselor-level data to examine whether there were systematic differences in the counselors stationed at UNM and at APS high schools. ${ }^{8}$ Therefore, we are uncertain about the extent to which the higher responsiveness of students to the college-side outreach is driven by stronger counselors being assigned to work from UNM for the summer. That being said, the counselors stationed at UNM did receive additional training, support and access to UNM resources. These additional supports, rather than simply a difference in counselor "quality" may have contributed to the increased student responsiveness to outreach. It is also possible that students' greater responsiveness to college-side outreach is emblematic of their comparative enthusiasm for communication from a university during this time period rather than from counselors stationed at the university being better equipped to support students with the transition to college. Either mechanism would point in favor of increased efforts from colleges and universities to proactively reach out and support intending students through to matriculation.

While the focal students in this intervention did not experience high rates of summer melt overall, we did uncover an important "pocket" of summer melt, even among these higher-achieving APS graduates. Specifically, among all students admitted to the University of New Mexico, the rate of summer melt among Hispanic males was substantially higher than for all other students. This finding is particularly important given the underrepresentation of males and of minority males, in particular, on college campuses across the US. In short, the overall strong rate of college matriculation among the UNM-admitted students masks far greater risk of melt for this important subgroup.

Encouragingly, for this key subgroup of students, summer outreach had a positive impact on on-time postsecondary matriculation. Specifically, summer outreach improved timely enrollment among Hispanic males by nearly 10 percentage points, bringing on-time enrollment for this subgroup essentially equivalent to that of all other students in the sample. When we examine the impact of outreach according to its source (i.e., high school versus university), we find that these students were significantly more responsive to college-side outreach. Further, we find suggestive evidence that the college-side outreach was particularly effective at improving timely enrollment among Hispanic males.

Nevertheless, while all of the students in our sample were admitted to the University of New Mexico, those who did continue to college directly after high school matriculated to a variety of institutions. Among control group students, 67\% enrolled at UNM, and nearly one-quarter enrolled at another college or university. Among Hispanic males, the overall treatment effect of outreach was essentially evenly divided between supporting students to enroll at the University of

\footnotetext{
${ }^{8}$ Further, because some counselors worked across multiple schools, and schools are de-identified in our dataset, we are unable to group students by the counselor from whom they received outreach. We are only able to observe whether students received outreach from a high-school or universitybased counselor.
} 
New Mexico and supporting them enroll in a different college or university. These patterns point to potential instability in students' postsecondary plans at the time of high school graduation.

This instability, in fact, is corroborated by information collected through the counselor interaction logs. Specifically, several counselors reported assisting students who, during the summer after high school, had changed their minds about the college or university which they wanted to attend. To the extent that students' postsecondary plans are still in flux during this summer, it may actually be inefficient for specific colleges and universities to invest substantially in summer outreach. While the expertise of a specific college would be directed towards helping a student enroll at that campus, students may benefit more from supported provided by counselors who are able to help them consider a fuller range of postsecondary options. More broadly, if support for the college transition is left solely to colleges and universities, students who intend to matriculate in college but who have not selected a specific institution may fly "below the radar" of the postsecondary sector. In fact, in prior interventions, we have found that summer outreach can be particularly beneficial for students who lack specific postsecondary plans at the time of graduation (Castleman \& Page, 2015).

A second concern is that colleges may be motivated to act in the best interest of their institution rather than in the best interest of the potential students to whom they are reaching out. If during this summer, students need the freedom to consider a host of postsecondary options or to work to identify new possibilities for themselves, the most appropriate support may come from their high school or from a communitybased organization, since these sectors do not have a vested financial interest in students enrolling at any particular postsecondary institution. Scaling such supports through the secondary school sector would involve systematic extension to counselors' contracts, given that school counselors are not typically "on-contract" through the summer months.

Yet another possibility for providing these summer transition supports at scale is for support delivery to be led by state education agencies. Like high schools and community-based organizations, state agencies do not have any inherent preference in students attending one institution over another. They also frequently have close collaborations with both high schools and colleges and can act as effective conveners of both sectors. For example, we currently have work underway with the West Virginia Higher Education Policy Commission (WV HEPC) and the Delaware Department of Education to implement state-level college transition initiatives. WV HEPC is implementing a text messaging campaign with all West Virginia high schools that participate in the federal GEAR UP college access program. Students in GEAR UP high schools began receiving text messages with financial aid and college planning information in January of their senior year. Students could write back to the messages and receive help from the GEAR UP coordinator at their high school. As students chose which college to attend, WV HEPC customized message content to their intended college and students' requests for help were routed to their intended institution. In Delaware, the Department of Education is providing person- alized text message reminders to high school seniors and their parents throughout the state. As in West Virginia, these messages provide personalized information and the offer of individualized advising assistance with financial aid and college planning. Where possible, messaging is customized according to relevant information. For example, based on regularly updated student-level FAFSA filing information held by the state, students who have not yet filed a FAFSA receive messages encouraging them to do so, while students who have already filed successfully received messages encouraging follow-up steps like confirming their Student Aid Report and applying for supplemental aid. Based on the successful implementation of this work, we see considerable potential to scale summer melt support to larger populations of students through state or other broad-reaching agencies.

\section{Acknowledgments}

We are grateful for the collaboration of the Albuquerque Public Schools (APS) and the University of New Mexico (UNM). Within APS, we particularly thank Leslie Kelly, Freida Trujillo, Phyllis Clay, Sade Bonilla, and the counselors who participated in the intervention. Within UNM, we thank Jennifer Gomez-Chavez and Vanessa Harris. We thank Bridget Terry Long and Eric Bettinger for feedback and guidance in the development of this intervention and for their facilitation of generous financial support from the Bill \& Melinda Gates Foundation. All opinions expressed in this paper and any errors or omissions are our own. Authorship order was determined alphabetically.

\section{References}

Bailey, M. J., \& Dynarski, S. M. (2011). Inequality in postsecondary education. In G. J. Duncan, \& R. J. Murnane (Eds.), Whither opportunity? Rising inequality, schools, and children's life chances. New York: Russell Sage Foundation.

Baum, S., Ma, J., \& Payea, K. (2013). Education pays 2013: The benefits of higher education for individuals and society.

Becker, G. S. (1964). Human capital: A theoretical and empirical analysis, with special reference to education. Chicago: University of Chicago Press.

Bettinger, E., Long, B. T., Oreopoulos, P., \& Sanbonmatsu, L. (2012). The role of application assistance and information in college decisions: Results from the H\&R Block FAFSA experiment. Quarterly Journal of Economics, 127(3), 1205-1242.

Bos, J., Berman, J., Kane, T., \& Tseng, F. (2012). The impacts of SOURCE: A program to support college enrollment through near-peer low-cost student advising, working paper.

Bryan, J., Holcomb-McCoy, C., Moore-Thomas, C., \& Day-Vines, N. (2009). Who sees the school counselor for college information? A national study. Professional School Counseling, 12(4), 280-291.

Card, D. (1999). The causal effect of education on earnings. Handbook of Labor Economics, 3, 1801-1863.

Carrell, S. E., \& Sacerdote, B. (2013). Late interventions matter too: The case of college coaching New Hampshire. National Bureau of Economic Research (No. w19031)

Castellanos, J., Gloria, A. M., \& Kamimura, M. (Eds.). (2006). The Latina/o pathway to the Ph.D.: Abriendo caminos. Stylus Publishing, LLC.

Castleman, B. L. (2015). Prompts, personalization, and pay-offs: Strategies to improve the design and delivery of college and financial aid information. In B. L. Castleman, S. Schwartz, \& S. Baum (Eds.), Decision making for student success. New York, NY: Routledge Press.

Castleman, B. L., \& Page, L. C. (2014). A trickle or a torrent? Understanding the extent of summer "melt" among college-intending high school graduates. Social Sciences Quarterly, 95(1), 202-220.

Castleman, B. L., \& Page, L. C. (2014). Summer melt: Supporting low-income students in the transition from high school to college. Cambridge, MA: Harvard Education Press. 
Castleman, B. L., \& Page, L. C. (2015). Summer nudging: Can personalized text messages and peer mentor outreach increase college going among low-income high school graduates? Journal of Economic Behavior and Organizations, 115, 144-160.

Castleman, B. L., Page, L. C., \& Schooley, K. (2014). The forgotten summer: The impact of college counseling the summer after high school on whether students enroll in college. The Journal of Policy Analysis \& Management, 33(2), 320-344

Cialdini, R. B. (2001). Influence: Science and practice. Boston, MA: Allyn \& Bacon.

Cohen, G. L., \& Garcia, J. (2005). "I am us": Negative stereotypes as collective threats. Journal of Personality and Social Psychology, 89(4), 566-582.

Constantine, M. G., Kindaichi, M., \& Miville, M. (2007). Factors influencing the educational and vocational transitions of Black and Latino high school students. Professional School Counseling, 10(3), 261-265.

Dale, S. B., \& Krueger, A. B. (2014). Estimating the return to college selectivity over the career using administrative earning data. Journal of Human Resources, 49, 323-358.

Dynarski, S. M. (2003). Does aid matter? Measuring the effect of student aid on college attendance and completion. American Economic Review, 93(1), 279-288.

Dynarski, S. M., Hemelt, S. W., \& Hyman, J. M. (2015). The missing manual using national student clearinghouse data to track postsecondary outcomes. Educational Evaluation and Policy Analysis, 37(1 Suppl.), 53S-79S.

Goldin, C. D., \& Katz, L. F. (2008). The race between education and technology. Cambridge, MA: Harvard University Press.

Goldin, C., Katz, L. F., \& Kuziemko, I. (2006). The homecoming of American college women: The reversal of the college gender gap. Journal of Economic Perspectives, 20(4), 133-156.

Goodman, S. (2013). Learning from the test: Raising selective college enrollment by providing information. Finance and Economics Discussion Series 2013-69. Board of Governors of the Federal Reserve System (U.S.)

Hansen, B. B., \& Bowers, J. (2008). Covariate balance in simple, stratified and clustered comparative studies. Statistical Science, 23(2), 219-236.

Hoxby, C., \& Avery, C. (2013). The missing "one-offs": The hidden supply of highachieving, low income students, Brookings Papers on Economic Activity.

Hoxby, C., \& Turner, S. (2013). Expanding college opportunities for highachieving, low income students (Stanford Institute for Economic Policy Research Discussion Paper, (12-014)).

Hurtado, S., Santos, J. L., Sáenz, V. B., \& Cabrera, N. L. (Eds.). (2008). Advancing in higher education: A portrait of Latina/o college freshmen at four-year institutions, 1975-2006. Higher Education Research Inst.

Kane, T. J. (2003). A quasi-experimental estimate of the impact of financial aid on college-going. National Bureau of Economic Research (No. w9703).

Karlan, D., McConnell, M., Mullainathan, S., \& Zinman, J. (2010). Getting to the top of mind: How reminders increase saving. National Bureau of Economic Research (No. w16205).
Klasik, D. (2012). The college application gauntlet: A systematic analysis of the steps to four-year college enrollment. Research in Higher Education, 53, 506-549

Lee, J.M., \& Rawls, A. (2010). The college completion agenda 2010 progress report. New York: The College Board.

Long, M. C. (2010). Changes in the returns to education and college quality. Economics of Education Review, 29(3), 338-347.

Lovelace, K., \& Rosen, B. (1996). Differences in achieving person-organization fit among diverse groups of managers. Journal of Management, 22(5), $703-722$.

Pallais, A. (2013). Small differences that matter: Mistakes in applying to college. National Bureau of Economic Research (No. w19480).

Roderick, M. R., Nagaoka, J., Coca, V., \& Moeller, E. (2008). From high school to the future: Potholes on the road to college. Chicago, IL: Consortium on Chicago School Research at University of Chicago.

Saenz, V. B., \& Ponjuan, L. (2008). The vanishing Latino male in higher education. Journal of Hispanic Higher Education, 81, 54-89.

Schochet, P.Z. (2008). Technical Methods Report: Guidelines for Multiple Testing in Impact Evaluations. NCEE 2008-4018. National Center for Education Evaluation and Regional Assistance.

Scott-Clayton, J. (2015). The shapeless river: Does a lack of structure inhibit students' progress community colleges? In B. L. Castleman, S. Schwartz, \& S. Baum (Eds.), Decision making for student success New York, NY: Routledge Press.

Smith, J., Pender, M., \& Howell, J. (2013). The full extent of student-college academic undermatch. Economics of Education Review, 32, 247-261.

Stephens, N. M., Hamedani, M. G., \& Destin, M. (2014). Closing the socialclass achievement gap: A difference-education intervention improves first-generation students' academic performance and all students' college transition. Psychological Science, 25(4), 943-953.

Strategic Data Project. (2014). Albuquerque Public Schools College-Going Diagnostic Issue Brief.

Walton, G. M., \& Cohen, G. L. (2007). A question of belonging: Race, social fit, and achievement. Journal of Personality and Social Psychology, 92(1), 82-96.

Walton, G. M., \& Cohen, G. L. (2011). A brief social-belonging intervention improves academic and health outcomes of minority students. Science, 331(6023), 1447-1451.

White, K. M., Hogg, M. A., \& Terry, D. J. (2002). Improving attitude-behavior correspondence through exposure to normative support from a salient ingroup. Basic and Applied Social Psychology, 24(2), 91-103.

Yeager, D. S., \& Dweck, C. S. (2012). Mindsets that promote resilience: When students believe that personal characteristics can be developed. Educational Psychologist, 47, 302-314.

Yeager, D. S., \& Walton, G. M. (2011). Social-psychological interventions in education They're not magic. Review of Educational Research, 81(2), 267301. 